\title{
Drug-coated Balloons or Drug-eluting Stents - Determining an Optimum Strategy for Patients with High Bleeding Risk
}

\author{
Natasha H Corballis, ${ }^{1,2}$ Tha H Nyi, ${ }^{3}$ Vassilios S Vassiliou ${ }^{1,2}$ and Simon C Eccleshall ${ }^{1}$ \\ 1. Department of Cardiology, Norfolk and Norwich University Hospital NHS Foundation Trust, Norwich, UK; 2. Norwich Medical School, \\ University of East Anglia, Bob Champion Research and Education, Norwich, UK; 3. Department of Acute Medicine, Norfolk and Norwich \\ University Hospital NHS Foundation Trust, Norwich, UK
}

DOI: https://doi.org/10.17925/HI.2020.14.2.100

$\mathrm{T}$ he management of patients who require percutaneous coronary intervention and are at high risk of bleeding continues to be challenging; balancing thrombotic risk versus bleeding risk to determine the safest duration of dual antiplatelet therapy (DAPT). With recent efforts to determine the safety of 1 month of DAPT after implantation of a drug-eluting stent, drug-coated balloons (DCBS) have also been explored, as both have been shown superior to bare-metal stents, which have historically been used for patients with high bleeding risk. We sought to review the literature surrounding the safety profile and bleeding events with both DCBS and drug-eluting stents, and conclude that while both offer safety of cessation of DAPT after 1 month, DCBS offer lower major adverse cardiovascular events.

\section{Keywords}

Drug-coated balloons, drug-eluting stents, high bleeding risk, duration of dual antiplatelet therapy

Disclosures: Vassilios Vassiliou reports speake fees from Medtronic and Daichii-Sankyo. Simon Eccleshall received speaker fees from and acts as a consultant for B Braun. Natasha Corballis and Tha $\mathrm{H}$ Nyi have no financial or non-financial relationships or activities to declare in relation to this article.

Review Process: Double-blind peer review.

Compliance with Ethics: This study involves a review of the literature and did not involve any studies with human or animal subjects performed by any of the authors.

Authorship: The named authors meet the International Committee of Medical Journal Editors (ICMJE) criteria for authorship of this manuscript take responsibility for the integrity of the work as a whole, and have given final approval for the version to be published.

Access: This article is freely accessible at touchCARDIO.com (c) Touch Medical Media 2020

Received: 10 November 2020

Accepted: 10 December 2020

Published Online: 23 December, 2020

Citation: Heart International. 2020;14(2):100-4

Corresponding author: Simon C Eccleshall,

Department of Cardiology, Norfolk and Norwich University Hospital NHS Foundation Trust, Norwich, NR4 7UY,UK.E: simon.eccleshall@nnuh.nhs.uk

Support: No funding was received in the publication of this manuscript.
Coronary artery disease is the leading cause of morbidity and mortality globally. ${ }^{1}$ Dual antiplatelet therapy (DAPT), in the form of aspirin and a P2Y ${ }_{12}$ inhibitor, is the mainstay of pharmacotherapeutic treatment for acute coronary syndrome and prevention of stent thrombosis after percutaneous coronary intervention (PCI) for acute coronary syndrome or stable coronary disease. DAPT with ticlopidine plus aspirin was first shown to be superior to anticoagulation and aspirin for patients undergoing PCI in 1996. ${ }^{2}$ Since then, DAPT of clopidogrel plus aspirin has been shown to be superior to aspirin alone, with a relative risk reduction of $26.9 \%$ for major adverse cardiovascular events (MACE). ${ }^{3}$ DAPT has since become one of the most extensively investigated treatment strategies in cardiology, with over 35 randomised controlled trials and 225,000 patients, and is increasingly important given the volume of patients requiring DAPT. In 2015, European-based population estimates suggested that 1.4-2.2 million patients require DAPT per year.

The duration of DAPT has evolved with the introduction of second- and now third-generation drug-eluting stents. First-generation drug-eluting stents raised the concern of very late stent thrombosis after 1 year, ${ }^{4}$ with evidence supporting prolonged duration of DAPT to prevent subsequent spontaneous myocardial infarction. ${ }^{5}$ This led to randomised controlled trials investigating prolonged duration of DAPT. The trade-off of reducing ischaemic sequelae is always balanced with the risk of bleeding, with evidence supporting a significant increase in bleeding events with 12 months of DAPT compared with $>12$ months of DAPT, with a minimal reduction in MACE (2.5\% versus $1.6 \%$ major bleeding, respectively; $p<0.001){ }^{6}$

Having established the safety of 1 month of DAPT after DCB angioplasty in stable coronary disease, we sought to review the evidence for shorter duration DAPT in terms of bleeding rates, clinical outcomes and safety profiles for both DCB and drug-eluting stents.

\section{Identifying bleeding risk and risk stratification}

Given the aging population and the increasingly complex co-morbidities that we are seeing, the risk of bleeding is greater. This has led to the introduction of bleeding risk stratification scoring systems both for clinical and research purposes. Both the DAPT and PARIS risk stratification scores were introduced based on prediction of events during index admission or shortly after. ${ }^{7.8}$ Neither of these stratification scores looked at the duration of DAPT in relation to bleeding risk. The most comprehensive scoring system to date is the PRECISE-DAPT scoring system, which is recommended by the European Society of Cardiology (ESC) guidelines as a class IIb A recommendation for use. The PRECISE-DAPT study showed that if patients considered at a high risk of bleeding were given a prolonged ( $>12$ months) duration of DAPT, there was no ischaemic benefit but a significantly higher bleeding risk with a number needed to harm of $38 .{ }^{9}$ 
Figure 1: The European Society of Cardiology recommendations for dual antiplatelet therapy after percutaneous coronary intervention for stable coronary disease

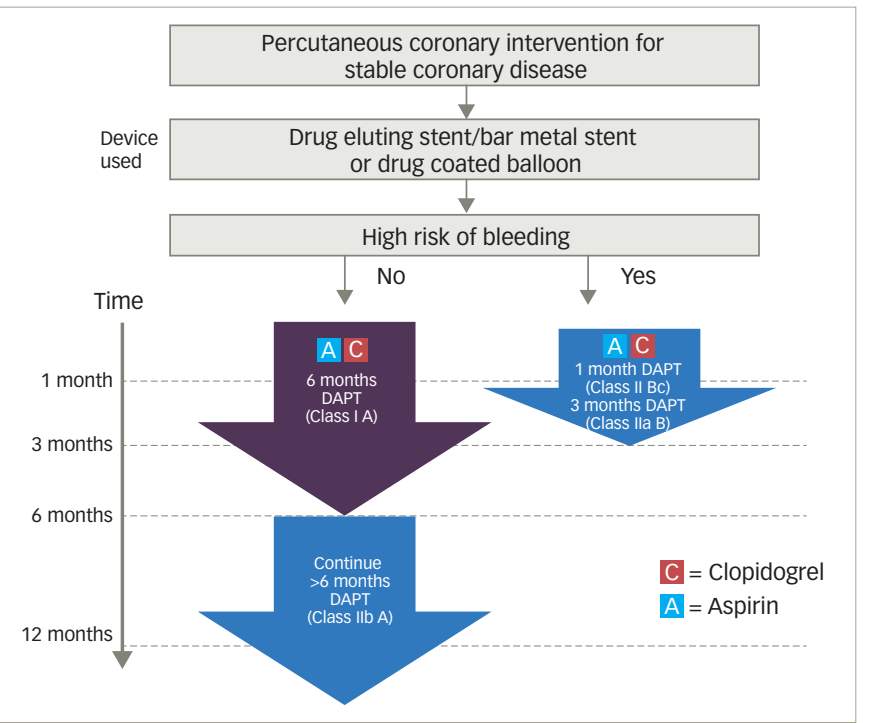

$D A P T=$ dual antiplatelet therapy.

\section{Guidelines}

DAPT guidelines are different for acute coronary syndrome and $\mathrm{PCl}$ in stable coronary disease. Regardless of bleeding risk, DAPT is recommended for 12 months for all patients after acute coronary syndrome. ${ }^{1}$ However, for patients undergoing PCl for stable coronary disease, the evidence is less cohesive. This becomes relevant for two reasons:

- as a stable group, there is time to plan the intervention strategy, assess bleeding risk and determine an appropriate approach to an individual patient; and

- there is less clear-cut evidence on the duration of DAPT for this cohort.

The current ESC guidelines for patients not at a high risk of bleeding with stable coronary disease treated with a drug-eluting stent/bare-metal stent or a drug-coated balloon (DCB), advise 6 months of DAPT (class I A recommendation) with a class IIb A recommendation to continue DAPT for a further 6 months (DAPT consisting of aspirin and clopidogrel) (Figure 1). For patients at a high risk of bleeding treated with drug-eluting stent/bare-metal stent or DCB, a 1-month duration of DAPT has a class IIb $\mathrm{C}$ recommendation, with 3 months of DAPT having a class Ila B recommendation. Despite these guidelines, routine clinical practice continues to give 12 months DAPT for patients receiving a drug-eluting stent for stable coronary disease unless there are significant bleeding sequelae. ${ }^{10}$

A systematic review and meta-analysis (17 studies, 46,864 patients) compared short-term ( $\leq 6$ months but excluded those with $\leq 1$ month) with standard duration of DAPT (12 months) and long duration DAPT ( $\geq 12$ months) for drug-eluting stents. This included all patients with acute coronary syndrome and stable coronary disease. It showed a statistically significant increase in all-cause mortality and major bleeding in the long-duration DAPT group, and an increase in any bleeding in the standard-duration DAPT group compared with the short-term duration DAPT group, with no statistically significant difference in MACE. ${ }^{11}$ While this systematic review identifies a 6-month duration of DAPT as safe, it does not explore the evidence supporting a duration of DAPT of less than
6 months. This meta-analysis did not identify whether patients were at a higher risk of bleeding.

\section{Drug-coated balloons - a practical alternative}

DCBS are an attractive proposition for cardiology interventionalists who subscribe to the 'leave nothing behind' philosophy. ${ }^{12}$ The use of DCBs is currently recommended by the ESC guidelines for in-stent restenosis. However, over the past 2 years, the evidence supporting the role of DCBS in wider circumstances has increased (Figure 2). ${ }^{13-27}$

One significant benefit of a DCB strategy is the proposed shorter duration of DAPT required. Previous consensus groups have all recommended 1 month of DAPT for stable coronary disease..$^{1728,29}$ This recommendation was changed by the 2017 ESC Focused DAPT Update, which recommended a 6-month duration of DAPT after DCB angioplasty. In response to this, a recent retrospective analysis of real-world registry data in 303 patients treated with 1 month of DAPT after elective DCB angioplasty, reported no occurrence of MACE at 6 months, and found that 1 month of DAPT appears safe after DCB angioplasty for stable coronary disease ${ }^{30}$ Further to this, recent work has confirmed long-term safety with 1 month of DAPT after elective DCB angioplasty, ${ }_{1}^{11}$ which is supported by the 36-month outcomes published in the BASKET-SMALL 2 trial. ${ }^{13}$ Table 1 provides a summary of all papers included in the review. ${ }^{13,15,32-36}$

\section{Drug-eluting stents with 1 month of dual antiplatelet therapy - improved safety profile}

There has been recent emphasis on identifying the safety of 1-month duration of DAPT for drug-eluting stents, given that studies suggest at least $15 \%$ of patients undergoing $\mathrm{PCl}$ are at a high risk of bleeding. ${ }^{37}$ Until recently, bare-metal stents were considered an appropriate strategy for patients at a high risk of bleeding, as 1 month of DAPT was deemed safe and adequate. This was despite all of the evidence showing superiority of drug-eluting stents compared with bare-metal stents, particularly in terms of target lesion revascularisation. ${ }^{38}$ In addition, there had been no safety or efficacy data supporting the use of drug-eluting stents for 1 month only. As such, significant advancements have been made in stent technology in improving the safety profile for a shorter duration of DAPT. This includes newer-generation drug-eluting stents, bioresorbable polymer and faster re-endothelisation combined with thinner struts, which all influence rates of stent thrombosis. ${ }^{39}$

The ZEUS, SENIOR and LEADERS FREE trials all changed perspectives on the use of bare-metal stents for patients with high bleeding risk, showing that the use of drug-eluting stents with 1 month of DAPT was superior in terms of safety and efficacy over the use of bare-metal stents with 1 month of DAPT. ${ }^{33,34,40}$ The LEADERS FREE trial randomised 2,466 patients, including those with acute coronary syndrome and stable coronary disease, to either second-generation drug-eluting stents or bare-metal stents with 1 month of DAPT. A primary safety endpoint of cardiac death, myocardial infarction or stent thrombosis showed drug-eluting stents to be superior to bare-metal stents (9.4\% versus $12.9 \%$, respectively; hazard ratio [HR] 0.71; $95 \%$ confidence interval [Cl] 0.56-0.91; $\mathrm{p}=0.005$ ). There was no statistically significance between bleeding events based on the Bleeding Academic Research Consortium (BARC) criteria for types 3-5 bleeding (7.2\% for the drug-eluting stent versus $7.3 \%$ for the bare-metal stent; $\mathrm{p}=0.96) .{ }^{40}$

The ZEUS study compared second-generation drug-eluting stents with bare-metal stents in a more heterogeneous population - those at high bleeding risk, high thrombotic risk or low restenosis risk. A subgroup analysis of patients at a high bleeding risk $(n=828)$ favoured drug-eluting stents over bare-metal stents with a primary composite outcome of 
Figure 2: Visual representation of the role of drug-coated balloons, their indication for use and evidence supporting their use in de novo coronary disease
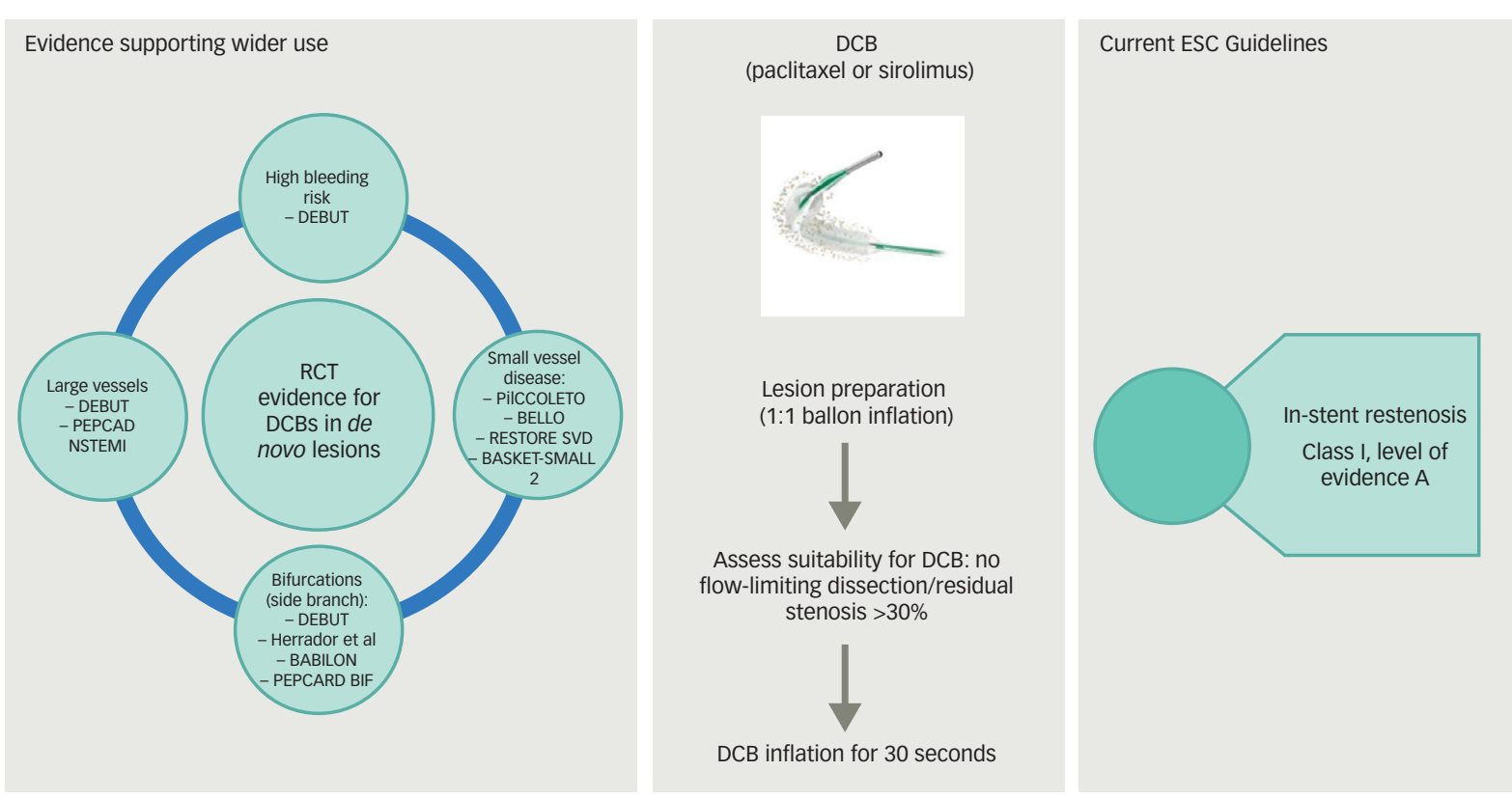

$D C B=$ drug-coated balloon; ESC = European Society of Cardiology; $R C T=$ randomised controlled trial.

Table 1: Summary of randomised controlled trials

\begin{tabular}{|c|c|c|c|c|c|}
\hline Study & Experimental arm & Control arm & Study population & Primary endpoint & Results \\
\hline \multicolumn{6}{|l|}{ DES } \\
\hline LEADERS FREE ${ }^{32}$ & $\begin{array}{l}\text { Second-generation } \\
\text { DES }\end{array}$ & BMS & $\begin{array}{l}\mathrm{n}=2,466 \\
\text { ACS and stable coronary disease (high } \\
\text { bleeding risk) }\end{array}$ & MACE (CD, MI, ST) at 390 days & $\begin{array}{l}9.4 \% \text { versus } 12.9 \%, \text { HR } 0.71 \\
(95 \% \mathrm{Cl} 0.56-0.91), p=0.005\end{array}$ \\
\hline ZEUS ${ }^{33}$ & $\begin{array}{l}\text { Second-generation } \\
\text { DES }\end{array}$ & BMS & $\begin{array}{l}\mathrm{n}=1,606 \\
\text { ACS and stable coronary disease (high } \\
\text { bleeding risk, high thrombotic risk or low } \\
\text { restenosis risk) }\end{array}$ & $\begin{array}{l}\text { MACE (all-cause mortality, MI, } \\
\text { TVR) at } 12 \text { months }\end{array}$ & $\begin{array}{l}\text { 17.5\% versus } 22.1 \%, \mathrm{HR} 0.76 \\
(95 \% \mathrm{Cl} 0.61-0.95), \mathrm{p}=0.001\end{array}$ \\
\hline SENIOR ${ }^{34}$ & $\begin{array}{l}\text { Second-generation } \\
\text { DES }\end{array}$ & BMS & 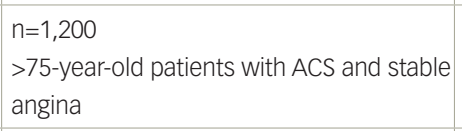 & $\begin{array}{l}\text { MACE (all-cause mortality, stroke, } \\
\text { MI, TLR) at } 12 \text { months }\end{array}$ & $\begin{array}{l}12 \% \text { versus } 16 \%, \mathrm{RR} 0.71 \\
(95 \% \mathrm{Cl} 0.52-0.94), \mathrm{p}=0.02\end{array}$ \\
\hline ONYX-ONE ${ }^{35}$ & $\begin{array}{l}\text { Zotarolimus-eluting } \\
\text { stent }\end{array}$ & Stent & $\begin{array}{l}\mathrm{n}=2,000 \\
\text { ACS and stable coronary disease (high } \\
\text { bleeding risk) }\end{array}$ & MACE (CD, MI, ST) at 12 months & $\begin{array}{l}17.1 \% \text { versus } 16.9 \% \text {, risk } \\
\text { difference } 0.2(95 \% \mathrm{Cl} \\
-3.1-3.5), p=0.01\end{array}$ \\
\hline STOPDAPT-2 ${ }^{36}$ & $\begin{array}{l}\text { DES with 1-month } \\
\text { DAPT }\end{array}$ & $\begin{array}{l}\text { DES with } 12 \\
\text { months DAPT }\end{array}$ & $\begin{array}{l}\mathrm{n}=3,045 \\
\text { ACS and stable coronary disease }\end{array}$ & $\begin{array}{l}\text { Combined cardiovascular and } \\
\text { bleeding composite endpoint }\end{array}$ & $\begin{array}{l}2.36 \% \text { versus } 3.7 \%, \text { HR } 0.64 \\
(95 \% \mathrm{Cl} 0.42-0.98), p=0.04\end{array}$ \\
\hline \multicolumn{6}{|l|}{ DCB } \\
\hline DEBUT 15 & DCB & BMS & $\begin{array}{l}\mathrm{n}=208 \\
\text { ACS and stable coronary disease (high } \\
\text { bleeding risk) }\end{array}$ & $\operatorname{MACE}(C D, M I, T L R)$ & $\begin{array}{l}0 \% \text { versus } 11 \%, \mathrm{HR} 0.35 \\
(95 \% \mathrm{Cl} 0.11-1.09), \mathrm{p}=0.069\end{array}$ \\
\hline BASKET-SMALL $2^{13}$ & DCB & DES & $\begin{array}{l}\mathrm{n}=758 \text { ACS \& stable coronary disease } \\
\text { (1-month DAPT only in stable group) }\end{array}$ & MACE (CD, MI, TVR) at 12 months & $\begin{array}{l}7.3 \% \text { versus } 7.5 \%, \mathrm{HR} 0.97 \\
(95 \% \mathrm{Cl} 0.58-1.64), \mathrm{p}=0.918)\end{array}$ \\
\hline
\end{tabular}

ACS = acute coronary syndrome; $B M S=$ bare-metal stent; $C D=$ cardiac death; $C l=$ confidence interval; $D A P T=$ dual antiplatelet therapy; $D C B=$ drug-coated balloon;

$D E S=$ drug-eluting stent; $H R=$ hazard ratio; $M A C E=$ major adverse cardiovascular outcomes; $M I=$ myocardial infarction; $R R=$ relative risk; $S T=$ stent thrombosis; TLR = target lesion revascularisation; TVR = target vessel revascularisation.

death, myocardial infarction or target vessel revascularisation (HR 0.74; $95 \% \mathrm{Cl} 0.57-0.97))^{33}$

The SENIOR trial randomised 1,200 patients over the age of 75 to either drug-eluting stents or bare-metal stents, and gave 1 month of DAPT for stable angina and 6 months for acute coronary syndrome. Although these patients were not specifically at high risk of bleeding, their age does contribute to bleeding risk. The primary endpoint was a composite of all-cause mortality, myocardial infarction, stroke or ischaemia-driven target lesion revascularisation, and results favoured drug-eluting stents (12\% versus $16 \%$ in the bare-metal stent group; relative risk $0.71 ; 95 \% \mathrm{Cl}$ $0.52-0.94 ; p=0.02$ ). Bleeding complications occurred in $5 \%$ of both arms. ${ }^{34}$ 
These three studies have shown the superiority of drug-eluting stents over bare-metal stents in patients at high risk of bleeding who would benefit from a shorter duration of DAPT. Having identified that drug-eluting stents are superior to bare-metal stents in this situation, further studies have sought to evaluate the safety of 1-month duration of DAPT compared with a longer duration. The more recent ONYX ONE trial, comparing the Onyx ${ }^{\mathrm{TM}}$ zotarolimus-eluting stent (Medtronic, Dublin, Ireland) with the BioFreedom ${ }^{\text {TM }}$ polymer-free drug-eluting stent (Biosensors International, Singapore) showed non-inferiority with 1 month of DAPT, although event rates were notably high with the primary composite safety endpoint (cardiac death, myocardial infarction, stent thrombosis) at 1 year (17.1\% in the zotarolimus-eluting stent group versus $16.9 \%$ in the polymer-free drug-eluting stent group). ${ }^{41}$

The STOPDAPT-2 trial randomised 3,045 patients in Japan to either 1 or 12 months of DAPT after $\mathrm{PCl}$ (of which, 38\% had acute coronary syndrome). A primary composite endpoint of cardiovascular and bleeding events (cardiac death, myocardial infarction, definite stent thrombosis, ischaemic or haemorrhagic stroke, or Thrombolysis in Myocardial Infarction risk score major or minor bleeding) showed superiority of 1-month DAPT (2.4\% versus 3.7\% in the 12-month DAPT group; HR 0.64; $95 \% \mathrm{Cl} 0.42-0.98 ; \mathrm{p}=0.04){ }^{36}$ Of note, the majority of patients were at low to intermediate risk of bleeding.

\section{Drug-coated balloons and 1 month of dual antiplatelet therapy}

Two prospective studies have been conducted reporting cardiovascular outcomes and bleeding events using DCB in one arm and either drug-eluting or bare-metal stents in the other arm. The first study, the DEBUT trial, was a randomised controlled trial comparing bare-metal stents with DCBS in patients at high risk of bleeding. This included patients with stable coronary disease or acute coronary syndrome in the form of non-ST segment elevation myocardial infarction/unstable angina but excluded ST segment elevation myocardial infarction. Three lesions (two patients) in the DCB group required bailout stenting. The occurrence of a primary outcome of MACE in stable angina was $0 \%$ in the DCB group versus 11\% in the bare-metal stent group (HR 0.35; $95 \%$ $\mathrm{Cl} 0.11-1.09 ; \mathrm{p}=0.069$ ). DEBUT also reported a $13 \%$ bleeding rate at 9 months in the DCB group, with $11 \%$ in bare-metal stent group ( $p=0.59$ ). This was in a high-risk bleeding cohort with 58\% (DCB cohort) on an oral anticoagulant and 29\% (DCB cohort) anaemic with additional risk factors for bleeding, including old age (>80 years old), stage $\geq 3$ chronic kidney disease, thrombocytopenia, frailty, synthetic liver dysfunction and previous intracranial haemorrhage or cerebrovascular accident. ${ }^{15}$

The second study was the BASKET-SMALL 2 trial. ${ }^{13}$ This was a randomised controlled trial comparing drug-eluting stents with DCBs for small vessel disease in 758 patients with acute coronary syndrome and stable coronary disease. The primary objective was non-inferiority of DCB. The patients who received a DCB for stable coronary disease were given 1 month of DAPT and those who had an acute coronary syndrome were given 12 months. The majority of patients included were those with stable coronary disease (70\% in the DCB group and $73 \%$ in the drug-eluting stent group). Risk of bleeding criteria were not specified in the patient cohort. MACE at 12 months were $7.3 \%$ in the DCB arm versus $7.5 \%$ in the drug-eluting stent arm (HR 0.97; 95\% $\mathrm{Cl} 0.58-1.64 ; \mathrm{p}=0.9180$ ). Major bleeding rates were low, at $1.1 \%$ in the DCB group versus $2.4 \%$ in the drug-eluting stent group $(\mathrm{p}=0.46)$. Lower rates occurred in the DCB cohort, but this was not of statistical significance. ${ }^{13}$
A retrospective database analysis of all patients receiving 1 month of DAPT, showing no occurrence of MACE at 6 months, further strengthens the safety argument for the use of DCBS in those at high risk of bleeding. ${ }^{30}$ While the current ESC guidelines recommend DCBS only for in-stent restenosis, ${ }^{42}$ there is randomised controlled trial evidence supporting their use in small vessels $(<3 \mathrm{~mm}) .{ }^{13}$ With some observational data supporting the use of DCBs in large vessels, including left main stem lesions, $23,3,1,4,4,4$ and upcoming randomised controlled trials being considered to further investigate the use of DCBs in large vessels, their role in patients with high bleeding risk is thought to increase.

\section{Acute coronary syndromes and duration of dual antiplatelet therapy}

The current guidelines still recommend 12 months' duration of DAPT for all patients with acute coronary syndrome, regardless of treatment strategy. Although the purpose of this review is to focus on stable coronary disease, it is worth briefly mentioning the evidence for DCBs and drug-eluting stents for acute coronary syndrome with 1 month of DAPT. Within the drug-eluting stent randomised controlled trials, patients with acute coronary syndrome made up a significant proportion of the numbers: $41 \%$ in LEADERS FREE, ${ }^{32} 63 \%$ in ZEUS, ${ }^{33} 46 \%$ in SENIOR, ${ }^{34} 52 \%$ in ONYX ONE, ${ }^{35}$ and $38 \%$ in STOPDAPT-2. ${ }^{36}$ In comparison, the only data for 1-month DAPT in DCB in acute coronary syndrome are in DEBUT, where patients with acute coronary syndrome account for $46 \%$ of patients. ${ }^{15}$ BASKET-SMALL 2 gave 12 months of DAPT to all patients with acute coronary syndrome. ${ }^{13}$ Therefore, although the clinical outcomes in DEBUT are excellent for DCBS, there is currently a smaller body of evidence supporting the use of 1-month DAPT in patients with acute coronary syndrome with DCB.

\section{Discussion}

When comparing the DEBUT data $(\mathrm{DCB})^{15}$ with the LEADERS FREE trial (drug-eluting stent versus bare-metal stents in high-risk bleeding patients), ${ }^{40}$ the bleeding rates reported in DEBUT are not as high as those reported in the LEADERS FREE trial, where bleeding events (BARC 1-5) were $18.1 \%$ versus $19.1 \%$ (drug-eluting stent versus bare-metal stent, respectively), compared with $13 \%$ versus $11 \%$ in DEBUT (DCB versus bare-metal stent, respectively). Although the DEBUT numbers are smaller, both studies evaluated high risk of bleeding. In comparison, the BASKET-SMALL 2 trial reported lower bleeding events, at $4 \%$ versus $9 \%$ (DCB versus drug-eluting stent, respectively), but this patient group was not identified as being at a higher risk of bleeding, which may explain the lower bleeding rates..$^{13}$

Of particular interest, however, is the fact that although the bleeding rates were slightly lower in DEBUT compared with LEADERS FREE, the MACE rates were significantly lower in the DEBUT trial ( $1 \%$ for DCB) than both the LEADERS FREE trial (9.4\%) and the ONYX ONE trial (17.1\% for the zotorolimus-eluting stent). ${ }^{35}$ Of course, these MACE rates cannot be directly compared; however, it certainly adds strength to the concept that DCB is a very appealing strategy for patients at high risk of bleeding. This is backed up by our registry data with $0 \%$ MACE rates at 6 months in patients who received 1 month of DAPT. ${ }^{30}$

Where the LEADERS FREE, SENIOR and ONYX ONE trials all report high MACE occurrence in the drug-eluting stent arm $(9.4 \%, 12 \%$ and $17.1 \%$, respectively), the results of the Japanese STOPDAPT-2 were significantly lower, with MACE rates at 2.36\%. One hypothesis for this could be the use of intracoronary imaging to optimise stent sizing in almost all patients, which is not standard western practice. 
With the exception of the STOPDAPT-2 trial, DCB studies show a significantly lower MACE rate when compared with drug-eluting stents or bare-metal stents. This adds weight to the argument that DCB is an attractive proposition for patients who are at a higher risk of bleeding, particularly in the stable angina cohort where bleeding risk can be assessed pre-procedure and angioplasty strategy planned accordingly.

\section{Limitations}

While all of the included drug-eluting stent studies have been conducted with large numbers, the sample sizes in the DEBUT and BASKET-SMALL 2 trials were smaller, although both studies were adequately powered to answer their primary outcome. As the population in all of the included studies varied from those at high risk of bleeding to a heterogeneous cohort, no definitive subgroup meta-analysis can be conducted that would add any weight to the available data.

\section{Conclusion}

In conclusion, we are increasingly faced with a more complex patient cohort with higher risk of bleeding associated with DAPT. Although it is clear that 6 months' duration of DAPT can be given with adequate effects on MACE with drug-eluting stents, the MACE rates remain high with only 1 month of DAPT in the drug-eluting stent randomised controlled trials. In comparison, 1 month of DAPT with DCB in the DEBUT study ${ }^{15}$ and in a large real-world registry analysis ${ }^{31}$ shows significantly lower MACE rates than the contemporaneous drug-eluting stent studies. This strengthens the viewpoint that DCB is a very attractive proposition for all patients with stable coronary disease identified as being at a high risk of bleeding.
1. Valgimigli M, Bueno $H$, Byrne RA, et al. 2017 ESC focused update on dual antiplatelet therapy in coronary artery disease developed in collaboration with EACTS. Eur Heart $\mathrm{s}$ 2018:39:213-60.

2. Schömig A, Neumann F-J, Kastrati A, et al. A randomized comparison of antiplatelet and anticoagulant therapy after the placement of coronary-artery stents. N Eng/ I Med. 1996;334:1084-9.

3. Steinhubl SR, Berger PB, Mann JT 3rd, et al. Early and sustained dual oral antiplatelet therapy following percutaneous coronary intervention: a randomized controlled trial. JAMA. 2002;288:2411-20

4. Grove ECL, Kristensen SD, Stent thrombosis: definitions, mechanisms and prevention, 2007. Available at: www.escardio. org/Journals/E-Journal-of-Cardiology-Practice/Volume-5/Stentthrombosis-definitions-mechanisms-and-prevention-TitleStent-thrombos (accessed 10 December 2020).

5. Mozaffarian D, Benjamin EJ, Go AS, et al. Executive summary: heart disease and stroke statistics-2016 update. Circulation. 2016:133:447-54.

6. Mauri L, Kereiakes DJ, Yeh RW, et al. Twelve or 30 months of dual antiplatelet therapy after drug-eluting stents. N Eng/ J Med. 2014;371:2155-66

7. Yeh RW, Secemsky EA, Kereiakes DJ, et al. Development and validation of a prediction rule for benefit and harm of dual antiplatelet therapy beyond 1 year after percutaneous coronary intervention. JAMA. 2016;315:1735-49.

8. Baber U, Mehran R, Giustino G, et al. Coronary thrombosis and major bleeding after $\mathrm{PCl}$ with drug-eluting stents: risk scores from PARIS. J Am Coll Cardiol. 2016;67:2224-34.

9. Costa F, van Klaveren $D$, James $S$, et al. Derivation and validation of the predicting bleeding complications in patients undergoing stent implantation and subsequent dual antiplatelet therapy stent implantation and subsequent dual antiplatelet therapy
(PRECISE-DAPT) score: a pooled analysis of individual-patient datasets from clinical trials. Lancet. 2017;389:1025-34.

10. National Institute for Health and Care Excellence, Stable angina: management clinical guideline [CG126]. Available at: www.nice.org.uk/guidance/CG126 (accesse 10 December 2020

11. Yin $\mathrm{SHL}, \mathrm{Xu}$ P, Wang B, et al. Duration of dual antiplatelet therapy after percutaneous coronary intervention with drug-eluting stent: systematic review and network meta-analysis. BMJ. 2019;365:12222

12. Wickramarachchi U, Eccleshall S. Drug-coated balloon-only angioplasty for native coronary disease instead of stents. Interv Cardiol Rev. 2016;11:110-5.

13. Jeger RV, Farah A, Ohlow M-A, et al. Drug-coated balloons for small coronary artery disease (BASKET-SMALL 2): an open-labe rmall coronary artery disease (BASKET-SMALL 2): an open

14. Vos NS, Fagel ND, Amoroso G, et al. Paclitaxel-coated balloon angioplasty versus drug-eluting stent in acute myocardial infarction. JACC Cardiovasc Interv. 2019:12:1691-9.

15. Rissanen TT, Uskela S, Eränen J, et al. Drug-coated balloon for treatment of de-novo coronary artery lesions in patients with high bleeding risk (DEBUT): a single-blind, randomised, non-inferiority trial. Lancet. 2019;394:230-9.
16. Merinopoulos I, Wickramarachchi U, Wardley J, et al. Day case discharge of patients treated with drug coated balloon only angioplasty for de novo coronary artery disease: a single center angioplasty for de novo coronary artery disease: a single cer

17. Cortese B, Berti S, Biondi-Zoccai G, et al. Drug-coated balloon reatment of coronary artery disease: a position paper of the Italian Society of Interventional Cardiology. Catheter Cardiovasc interv. 2014;83:427-35

18. Cortese B, Micheli A, Picchi A, et al. Paclitaxel-coated balloon versus drug-eluting stent during $\mathrm{PCl}$ of small coronary vessels, a prospective randomised clinical trial. The PICCOLETO study. Heart. 2010;96:1291-6.

19. Latib A, Ruparelia N, Menozzi A, et al. 3-year follow-up of the Balloon Elution and Late Loss Optimization Study (BELLO). JACC Cardiovasc Interv. 2015;8:1132-4.

20. Tang Y, Qiao S, Su X, et al. Drug-coated balloon versus drug-eluting stent for small-vessel disease: The RESTORE SVD China randomized trial. JACC Cardiovasc Interv. 2018:11:2381-92.

21. Jeger JV, Farah A, Ohlow M-A, et al. Drug-coated balloons for small coronary artery disease (BASKET-SMALL 2): an open-labe randomised non-inferiority trial. Lancet. 2018;392:849-56.

22. Rissanen TT, Uskela S, Eränen J, et al. Drug-coated balloon for reatment of de-novo coronary artery lesions in patients with high bleeding risk (DEBUT): A single-blind, randomised, non-inferiority trial. Lancet. 2019;394:230-9.

23. Scheller B, Ohlow M-A, Ewen S, et al. Bare metal or drug-eluting stent versus drug-coated balloon in non-ST-elevation myocardial infarction: the randomised PEPCAD NSTEMI trial. Eurolntervention. 2020:15:1527-33.

24. Stella PR, Belkacemi A, Dubois C, et al. A multicenter randomized comparison of drug-eluting balloon plus bare-metal stent versus bare-metal stent versus drug-eluting stent in bifurcation lesions treated with a single-stenting technique: six-month angiographic and 12-month clinica results of the drug-eluting baloon in bifurcations trial. results of the drug-eluting baloon in bifurcations
Catheter Cardiovasc Interv. 2012:80:1138-46.

25. Herrador JA, Fernandez JC, Guzman M, Aragon V. Drug-eluting vs. conventional balloon for side branch dilation in coronary bifurcations treated by provisional T stenting. I Interv Cardiol. 2013;26:454-62

26. Mínguez JRL, Asensio JMN, Vecino LD, et al. A prospective randomised study of the paclitaxel-coated balloon catheter in bifurcated coronary lesions (BABILON trial): 24-month clinical and angiographic results. Eurolntervention. 2014:10:50-7.

27. Kleber FX, Rittger H, Ludwig J, et al. Drug eluting balloons as stand alone procedure for coronary bifurcational lesions: stand alone procedure for coronary bifurcational lesions:
results of the randomized multicenter PEPCAD-BIF trial. Clin Res Cardiol. 2016:105:613-21.

28. Chen Y, Wang J, Liu B, et al. China expert consensus on clinical application of the drug coated balloon. Cardiol Plus. 2016;1:41-8

29. Kleber F, Mathey D, Rittger H, Scheller B. German Drug-eluting Balloon Consensus Group. How to use the drug-eluting balloon: recommendations by the German consensus group. Eurolntervention. 2011;7:K125-8.
30. Corballis NH, Wickramarachchi U, Vassiliou VS, Eccleshall SC. Duration of dual antiplatelet therapy in elective drug-coated balloon angioplasty. Catheter Cardiovasc Interv. 2020:96:1016-20

31. Merinopoulos I, Gunawardena T, Wickramarachchi U, et al. Long-term safety of paclitaxel drug-coated balloon-only angioplasty for de novo coronary artery disease: the SPARTAN DCB study. Clin Res Cardiol. 2021;110:220-7.

32. Urban P, Abizaid A, Chevalier B, et al. Rationale and design of the LEADERS FREE trial: a randomized double-blind compariso of the BioFreedom drug-coated stent vs the Gazelle bare metal stent in patients at high bleeding risk using a short (1 month) course of dual antiplatelet therapy. Am Heart J. 2013;165:704-9.

33. Valgimigli M, Patialiakas A, Thury A, et al. Zotarolimus-eluting versus bare-metal stents in uncertain drug-eluting stent candidates. J Am Coll Cardiol. 2015;65:805-15.

34. Varenne $\mathrm{O}$, Cook S, Sideris G, et al. Drug-eluting stents in elderly patients with coronary artery disease (SENIOR): a randomised single-blind trial. Lancet. 2018:391:41-50.

35. Windecker S. Onyx One: A randomized trial of durable-polymer drug-eluting stent vs. a polymer-free drug-coated stent in patients at high risk of bleeding treated with 1-month DAPT. 2019. Available at: www.tctmd.com/slide/ onyx-one-randomized-trial-durable-polymer-drug-eluting-stentvs-polymer-free-drug-coated (accessed 11 December 2020).

36. Watanabe H, Domei T, Morimoto T, et al. Effect of 1-month dual antiplatelet therapy followed by clopidogrel vs 12-month dual antiplatelet therapy on cardiovascular and bleeding events in patients receiving PCI. JAMA. 2019;321:2414-27.

37. Morice $M-C$, Urban $P$, Greene $S$, et al. Why are we still using coronary bare-metal stents? J Am Coll Cardiol. 2013;61:1122-3.

Bønaa KH, Mannsverk J, Wiseth R, et al. Drug-eluting or bare-metal stents for coronary artery disease. N Eng/ I Med. 2016;375:1242-52.

39. Verdoia M, Kedhi E, Suryapranata $\mathrm{H}$, et al. Benefits of short-term or prolonged as compared to standard 1 year DAPT in patients with acute coronary syndrome treated with drug-eluting stents: a meta-analysis of 9 randomized trials. I Thromb Thrombolysis. 2020;50:337-54

40. Urban P, Meredith IT, Abizaid A, et al. Polymer-free drug-coated coronary stents in patients at high bleeding risk. N Eng/ J Med. 2015;373:2038-47

41. Windecker S, Latib A, Kedhi E, et al. Polymer-based or polymer-free stents in patients at high bleeding risk. N Eng/ J Med. 2020;382:1208-18.

42. Neumann F-J, Sousa-Uva M, Ahlsson A, et al. 2018 ESC/EACTS guidelines on myocardial revascularization Eur Heart J. 2019:40:87-165.

43. Wöhrle 」, Zadura M, Möbius-Winkler S, et al. SeQuentPlease World Wide Registry: clinical results of SeQuent please paclitaxel-coated balloon angioplasty in a large-scale prospective registry study. J Am Coll Cardiol. 2012; 60:1733-8

44. Wickramarachchi U, Corballis NH, Maart CA, et al. 21 Drug coated balloon-only angioplasty in left main stem disease, a UK single centre experience. Heart. 2017;103(Suppl. 7):A9-10. 